\title{
Estimação de parâmetros genéticos em tamanho de leitegada de suínos utilizando análises de características múltiplas
}

\author{
Leandro Barbosa ${ }^{1 \star}$, Paulo Sávio Lopes ${ }^{2}$, Adair José Regazzi ${ }^{3}$, Robledo de Almeida Torres ${ }^{2}$, \\ Mário Luiz Santana Junior ${ }^{1}$, Renata Veroneze ${ }^{4}$
}

\author{
1 Pós-Graduação UFV - Av. Ph Rolfs, s/n, Viçosa-MG - CEP:36570-000. Bolsista da CAPES. \\ 2 Departamento de Zootecnia, UFV, Av. P.H. Rolfs, s/n, Viçosa-MG - CEP: 36570-000. Bolsista do CNPq. \\ ${ }^{3}$ Departamento de Informática, UFV, Av. P.H. Rolfs, s/n, Viçosa-MG - CEP: 36570-000. Bolsista do CNPq. \\ ${ }^{4}$ Curso de Graduação em Zootecnia da UFV - Av. Ph Rolfs, s/n, Viçosa-MG - CEP: 36570-000. Bolsista da FAPEMIG.
}

RESUMO - Registros de animais da raça Large White foram utilizados para estimar componentes de co-variâncias e parâmetros genéticos para a característica número de leitões nascidos como medida do tamanho de leitegada. Na obtenção dos componentes de co-variâncias e dos parâmetros genéticos, utilizou-se o método da Máxima Verossimilhança Restrita, com o algoritmo Livre de Derivadas, por meio do programa MTDFREML. O modelo misto continha o efeito fixo de grupo contemporâneo e os efeitos aleatórios genético aditivo direto e residual. Dados das primeiras quatro parições foram usados em duas análises: análises unicaracterísticas e análise multicaracterística separada em séries de análises bicaracterísticas, na qual cada parição foi tratada como característica diferente. As estimativas de herdabilidades aditivas diretas para as parições obtidas nas análises multicaracterísticas foram consistentes com as estimativas obtidas nas análises unicaracterísticas, que variaram de 0,14 a 0,20. Estimativas de correlação fenotípica foram menores que as correlações genéticas. As correlações genéticas foram menores que 0,75 em todas as parições, exceto entre a terceira e a quarta parição, cuja correlação foi alta $(0,91)$. A menor correlação genética foi observada entre a primeira e a segunda ordem de parto $(0,60)$.

Palavras-chave: características reprodutivas, correlação genética, herdabilidade, número de leitões nascidos, REML

\section{Estimation of genetic parameters for litter size in pigs using multi-trait analyses}

\begin{abstract}
Data from the first four parities of Large White pigs were used to estimate (co)variance components and genetic parameters for litter size (LS) in single trait and multi-trait analyses. The (co)variance components and genetic parameters were estimated by restricted maximum likelihood using the MTDFREML program. LS in each parity was considered a different trait and the models included contemporary group as fixed effect and additive direct genetic and residual as random effects. Heritability estimates of LS in different parities in single trait analyses ranged from 0.14 to 0.20 . Estimates of heritability in multi-trait analyses were similar to those obtained in single trait analyses. Phenotypic correlation estimates were lower than the genetic ones. Genetic correlations between parities were lower than 0.75 , except for the estimate between the third and fourth parities, which was the highest one (0.91). The smallest genetic correlation $(0.60)$ was observed between the first and second parities.
\end{abstract}

Key Words: genetic correlation, heritability, litter size at birth, REML, reproductive traits

\section{Introdução}

Nos programas comerciais de melhoramento de suínos, tem-se enfatizado as características reprodutivas nas linhas fêmeas (Hanenberg et al., 2001). Vários autores têm demonstrado a efetividade na seleção para tamanho de leitegada (Knap et al., 1993; Lamberson et al., 1991; Sorensen \& Vernersen, 1991).
A seleção para prolificidade em porcas tem se concentrado no número de leitões ao nascimento (Southwood \& Kennedy, 1991; De Vries \& Kanis, 1994; Estany \& Sorensen, 1995).

O tamanho de leitegada é o principal componente da produtividade da porca e o foco do melhoramento genético é aumentar sua importância em mercados nos quais outras características, como ganho de peso e espessura de toucinho, 
já alcançaram níveis ótimos (Sorensen, 1991) ou no fato de que o aumento da prolificidade da porca reduz, significativamente, os custos de produção. No entanto, acuradas estimativas de parâmetros genéticos para tamanho de leitegada são essenciais para estimação dos valores genéticos e otimização da predição da resposta genética à seleção.

Heterogeneidade de herdabilidade para número de leitões nascidos vivos em diferentes parições e correlações fenotípicas menores que 0,9 entre parições sugerem o uso de modelos multicaracterísticos em vez de modelo de repetibilidade para avaliação genética de candidatos à seleção (Noguera et al., 2002).

Vários autores sugerem que, em parte, diversos genes controlam as características reprodutivas nas sucessivas parições (Roehe \& Kennedy, 1995; Hermesch et al., 2000; Noguera et al., 2002), indicando que parições diferentes devem ser tratadas como características diferentes.

Em suínos Large White, como em outras raças, o tamanho de leitegada tem sido analisado utilizando-se o modelo de repetibilidade, no qual tamanhos de leitegada de diferentes parições são medidas repetidas da mesma característica, no entanto, alguns autores têm sugerido que o efeito genético para tamanho de leitegada pode diferir entre parição (Vangen, 1986; Haley et al., 1988). Assim, se esta última situação for verdadeira, uma análise multicaracterística deveria ser executada para o aumento da eficiência de seleção para tamanho de leitegada e a obtenção de predições nãoviesadas da resposta genética esperada (Tartar \& Bolet, 1984).

Objetivou-se, neste estudo, estimar os parâmetros genéticos para tamanho de leitegada em diversas parições em análises de características múltiplas.

\section{Material e Métodos}

Os dados utilizados neste trabalho são de suínos da raça Large White, provenientes de uma granja localizada no oeste do estado de Santa Catarina.

Os leitões nasceram no período de 1996 a 2006 e, ao nascimento, foram submetidos ao corte dos dentes, à mossagem e à pesagem e aplicação de ferro dextrano. Realizou-se a padronização de leitegada, de modo que os leitões foram redistribuídos em um processo de equalização de leitegada por número e classe de peso (três classes). Até a desmama \pm 21 dias), houve outra equalização entre as leitegadas das porcas que pariram na mesma semana.

A característica número total de leitões nascidos (vivos + mortos) foi analisada como medida do tamanho de leitegada. Em razão do pequeno número de observações nas parições subseqüentes e por se tratar de granja núcleo, utilizaram-se somente as observações das quatro primeiras parições.

Como efeitos fixos, foram utilizados os grupos contemporâneos, formados pela combinação de ano e estação de parição: da $1 \underline{a}$ à $13 \underline{a}$ semana; da $14 \underline{a}$ à $27 \underline{a}$ semana; da $28 \underline{a}$ à

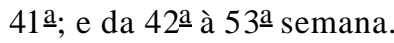

Na obtenção dos componentes de co-variância, utilizou-se o método da Máxima Verossimilhança Restrita, com o algoritmo Livre de Derivadas, por meio do programa MTDFREML (Boldman et al., 1995).

Para examinar as diferenças genéticas entre as parições, foram realizadas análises unicaracterísticas com efeito genético aditivo em modelos com cada parição e análises multicaracterísticas separadas em seis combinações de análises bicaracterísticas, em que o número de leitões em cada ordem de parto foi tratado como característica diferente.

O modelo animal (unicaracterístico) usado na análise foi:

$$
y=X b+Z d+e
$$

em que: $y=$ vetor de observações; $b=$ vetor de efeitos fixos de grupo contemporâneo; $X=$ matriz de incidência de efeitos fixos de grupo contemporâneo; $d=$ vetor de efeitos genéticos aditivos; $Z=$ matriz de incidência de efeitos genéticos aditivos; $e=$ vetor de efeito residual.

As análises de características múltiplas foram separadas em seis análises bicaracterísticas utilizando-se o modelo:

$$
\left[\begin{array}{l}
y_{1} \\
y_{2}
\end{array}\right]=\left[\begin{array}{cc}
X_{1} & 0 \\
0 & X_{2}
\end{array}\right]\left[\begin{array}{l}
b_{1} \\
b_{2}
\end{array}\right]+\left[\begin{array}{cc}
Z_{1} & 0 \\
0 & Z_{2}
\end{array}\right]\left[\begin{array}{l}
d_{1} \\
d_{2}
\end{array}\right]+\left[\begin{array}{l}
e_{1} \\
e_{2}
\end{array}\right]
$$

em que $y_{1}$ e $y_{2}$ representam o número de leitões nascidos em diferentes parições (considerado características diferentes). $O$ vetor de efeito fixo para a característica $1\left(b_{1}\right)$ e característica $2\left(b_{2}\right)$ foi o mesmo descrito no modelo unicaracterístico. Os vetores $d_{1}$ e $d_{2}$ são os efeitos genéticos aditivos e $e_{1}$ e $e_{2}$, os efeitos residuais para as características 1 e 2 , respectivamente. As matrizes de incidências $X_{1}$ e $X_{2}$ $\left(Z_{1}\right.$ e $\left.Z_{2}\right)$ associam elementos de $b_{1}$ e $b_{2}\left(d_{1}\right.$ e $\left.d_{2}\right)$ com as observações em $y_{1}$ e $y_{2}$.

No modelo bicaracterístico, a esperança de $y_{1}$ e $y_{2}$ e a estrutura das co-variâncias dos efeitos aleatórios são determinadas por:

$$
\begin{gathered}
E\left[\begin{array}{l}
y_{1} \\
y_{2}
\end{array}\right]=\left[\begin{array}{l}
X_{1} b \\
X_{2} b
\end{array}\right] \\
V\left[\begin{array}{l}
d_{1} \\
d_{2} \\
e_{1} \\
e
\end{array}\right]=\left[\begin{array}{cccc}
A \sigma_{d 1}^{2} & A \sigma_{d 12} & 0 & 0 \\
A \sigma_{d 21} & A \sigma_{d 2}^{2} & 0 & 0 \\
0 & 0 & I \sigma_{e 1}^{2} & I \sigma_{e 12} \\
0 & 0 & I \sigma_{e 21} & I \sigma_{e 2}^{2}
\end{array}\right]
\end{gathered}
$$

(c) 2008 Sociedade Brasileira de Zootecnia 
em que $\sigma_{d 1}^{2}$ e $\sigma_{d 2}^{2}=$ variâncias genéticas aditivas diretas; e $\sigma_{e 1}^{2}$ e $\sigma_{e 2}^{2}=$ variâncias residuais para as características 1 e 2 , respectivamente; $\sigma_{d 12}=$ co-variância genética aditiva entre as características 1 e 2 ; e $\sigma_{e 12}=$ co-variância residual entre as características 1 e 2 .

Cada análise foi reiniciada com diversos valores iniciais, a fim de garantir que os valores dos componentes estimados correspondessem ao máximo absoluto da função de verossimilhança, na tentativa de evitar a convergência para máximos locais. Como critério de convergência, foi considerada a variância do "Simplex" inferior a $10^{-9}$.

\section{Resultados e Discussão}

Os coeficientes de variação, as médias e os desviospadrão foram similares nas diferentes parições, o mesmo foi observado para número de grupos contemporâneos. Entretanto, o número de animais com observação decresceu à medida aumentou a ordem de parto (Tabela 1), inviabilizando o uso de maiores ordens de parto na análise. Haley et al. (1988) observaram, em revisão de literatura, que, embora a herdabilidade para tamanho de leitegada seja de baixa magnitude, a magnitude do coeficiente de variação é maior em relação às características de crescimento e carcaça.

A estimativa de herdabilidade neste estudo (Tabela 2) foi menor no modelo para a primeira ordem de parto em comparação à dos modelos das demais ordens de parto. A mesma tendência foi observada para a estimativa de variância genética aditiva e variância fenotípica e residual.

Neste estudo, a herdabilidade, em geral, aumentou de acordo com a ordem de parto, o que sugere a existência de diferentes bases genéticas atuando no tamanho de leitegada ao longo da vida reprodutiva da porca. Irgang et al. (1994)

Tabela 1 - Estrutura dos dados, médias e desvio-padrão para número de leitões nascidos em porcas da raça Large White em diversas ordens de parto

\begin{tabular}{lcccc}
\hline \multirow{2}{*}{ Item } & \multicolumn{4}{c}{ Valor } \\
\cline { 2 - 5 } & $\begin{array}{c}1 \underline{\underline{o}} \\
\text { parto }\end{array}$ & $\begin{array}{c}2 \underline{\underline{o}} \\
\text { parto }\end{array}$ & $\begin{array}{c}3 \underline{\underline{o}} \\
\text { parto }\end{array}$ & $\begin{array}{c}4 \underline{\underline{o}} \\
\text { parto }\end{array}$ \\
\hline Número de animais na $\mathrm{A}^{-1}$ & 58.628 & 58.628 & 58.628 & 58.628 \\
Total de observações & 3.211 & 3.211 & 3.211 & 3.211 \\
Número de animais & 3.208 & 1.711 & 1.062 & 589 \\
com observações & & & & \\
Número de grupos & 41 & 40 & 38 & 37 \\
contemporâneos & & & & \\
Número de porcas & 1.607 & 1.607 & 1.607 & 1.607 \\
Número de varrões & 370 & 370 & 370 & 370 \\
Número de leitões nascidos & & & & \\
Média & 10,99 & 10,68 & 11,55 & 11,81 \\
Desvio-padrão & 3,23 & 3,47 & 3,41 & 3,35 \\
Coeficiente de variação $(\%)$ & 29,40 & 32,51 & 29,55 & 28,39 \\
\hline
\end{tabular}

Tabela 2 - Estimativas de componentes de variância e herdabilidade usando modelo unicaracterístico para as diversas ordens de parto, para a característica número de leitões nascidos em suínos da raça Large White

\begin{tabular}{lcccc}
\hline Parâmetro & $\begin{array}{c}1^{\underline{\underline{o}}} \\
\text { parto }\end{array}$ & $\begin{array}{c}2^{\underline{0}} \\
\text { parto }\end{array}$ & $\begin{array}{c}3^{\underline{\underline{o}}} \\
\text { parto }\end{array}$ & $\begin{array}{c}4 \underline{\underline{o}} \\
\text { parto }\end{array}$ \\
\hline$\sigma_{d}^{2}$ & 1,47 & 2,33 & 2,39 & 1,98 \\
$\sigma_{e}^{2}$ & 8,87 & 9,79 & 9,27 & 9,36 \\
$\sigma_{p}^{2}$ & 10,33 & 12,13 & 11,65 & 11,35 \\
$\mathrm{~h}^{2}$ & 0,14 & 0,19 & 0,20 & 0,18 \\
& $(0,03)^{*}$ & $(0,05)^{*}$ & $(0,06)^{*}$ & $(0,09)^{*}$
\end{tabular}

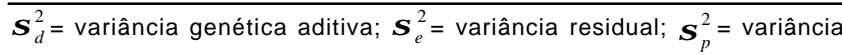
fenotípica; $h^{2}=$ herdabilidade

* Erro-padrão.

e Roehe \& Kennedy (1995) também obtiveram maiores herdabilidades nas últimas parições em comparação às primeiras, quando utilizaram análises unicaracterística ou bicaracterística.

Esses resultados estão de acordo com os relatados por Le Roy et al. (1987) e Bolet et al. (1989), que observaram tendência geral para aumentar a eficiência da seleção, em decorrência da herdabilidade, em parições mais tardias na vida do animal. Tartar (1981) demonstrou teoricamente que seleção na média das cinco primeiras parições resulta em grande resposta nas últimas parições.

Noguera et al. (2002) observaram estimativas de herdabilidade para número de leitões nascidos vivos em torno de 0,10, o que está de acordo com dados descritos na literatura (Haley et al., 1988; Lamberson, 1990; Rothschild \& Bidanel, 1998). Entretanto, Roehe (1999) obteve herdabilidade de 0,075 para número de leitões nascidos vivos. Em muitos desses estudos, os autores postularam herdabilidades homogêneas para todas as parições. Nesta pesquisa, observou-se heterogeneidade de herdabilidade entre as parições, assim como nos estudos reportados por Noguera et al. (2002).

Avalos \& Smith (1987) demonstraram que, com herdabilidade de 0,10 e uso de toda informação de família na seleção, pode ser alcançado melhoramento no tamanho de leitegada de 0,5 leitão por geração. Roehe \& Kennedy (1993) mostraram, por meio de simulação estocástica, que, com mais de dez anos de seleção, uma resposta de 0,22 leitão por ano pode ser atingida usando modelo animal e selecionando somente para tamanho de leitegada.

A menor estimativa da variância genética aditiva (Tabela 3) foi observada no primeiro parto e a maior, no segundo parto. Contudo, houve redução da variância genética aditiva do segundo até o quarto parto. Quando se 
Tabela 3 - Estimativas da variância genética aditiva ${ }^{\mathrm{a}}$ (na diagonal) e co-variâncias genéticas aditivas (abaixo da diagonal) e fenotípicas (acima da diagonal) entre as ordens de parto para número de leitões nascidos em suínos da raça Large White usando modelo multicaracterístico

\begin{tabular}{lcccc}
\hline & $\begin{array}{c}1 \underline{\mathrm{o}} \\
\text { parto }\end{array}$ & $\begin{array}{c}2 \underline{\mathrm{o}} \\
\text { parto }\end{array}$ & $\begin{array}{c}3 \underline{\mathrm{o}} \\
\text { parto }\end{array}$ & $\begin{array}{c}4 \underline{\mathrm{o}} \\
\text { parto }\end{array}$ \\
\hline 1 o parto & $1,46 \mathrm{~b}$ & 2,27 & 1,55 & 1,62 \\
2ㅇ parto & 1,10 & 2,41 & 3,46 & 1,45 \\
3을 parto & 1,21 & 1,67 & 2,33 & 2,93 \\
4으 parto & 1,11 & 1,88 & 1,84 & 2,08 \\
\hline
\end{tabular}

a Estimativas obtidas das análises bicaracterísticas entre as parições.

b Estimativas de cada ordem de parto são médias de três análises bicaracterísticas.

consideram diversas parições como várias características, é importante a correlação genética entre as parições para otimizar programas de melhoramento e predizer a resposta genética à seleção.

As estimativas de herdabilidade da análise multicaracterística entre as parições foram similares às estimativas obtidas das análises unicaracterísticas (Tabela 4). As estimativas de correlação fenotípica foram menores se comparadas às correlações genéticas, inferiores a 0,75 para todas as parições, exceto entre a terceira e a quarta parição, nas quais houve alta correlação $(0,91)$. A menor correlação genética foi observada entre a primeira e a segunda parição $(0,60)$.

Esses resultados corroboram os encontrados por Roehe \& Kennedy (1995), que também observaram menor correlação genética $(0,59)$ entre a primeira e a segunda parição para número de leitões nascidos totais em suínos da raça Yorkshire. Por outro lado, a maior correlação $(0,91)$ foi observada entre as duas últimas parições (terceira e quarta). A mesma tendência de correlações maiores nas parições posteriores foi observada por Hanenberg et al. (2001), que observaram aumento de 0,79 entre a primeira e a segunda parição para 0,96 entre a quinta e a sexta parição.

Lukovic et al. (2004) constataram correlações genéticas altas entre parições adjacentes $(0,80$ a 0,99$)$, que diminuíram à medida que as diferenças entre os pares de parições aumentaram. Segundo esses autores, correlações genéticas entre pares de parições adjacentes aumentam de acordo com o número de parições.

A magnitude da correlação entre parições é importante para definir o processo de avaliação ótimo a fim de que os programas de seleção possam melhorar o tamanho de leitegada em suínos. Irgang et al. (1994) observaram correlações genéticas baixas $(0,32$ a 0,48$)$ entre a primeira e a segunda parição em três raças de suínos. Entretanto,
Tabela 4 - Estimativas de herdabilidade ${ }^{a}$ (na diagonal) e correlações genéticas (abaixo da diagonal) e fenotípicas (acima da diagonal) entre as ordens de parto para número de leitões nascidos em suínos da raça Large White usando modelo multicaracterístico

\begin{tabular}{|c|c|c|c|c|}
\hline & $\begin{array}{c}1 \underline{\mathrm{o}} \\
\text { parto }\end{array}$ & $\begin{array}{c}2^{\underline{o}} \\
\text { parto }\end{array}$ & $\begin{array}{c}3^{\underline{o}} \\
\text { parto }\end{array}$ & $\begin{array}{c}4^{\mathrm{o}} \\
\text { parto }\end{array}$ \\
\hline $1^{\mathrm{o}}$ parto & $0,14 b$ & 0,13 & 0,04 & 0,06 \\
\hline $2^{-}$p parto & 0,60 & 0,20 & 0,19 & 0,15 \\
\hline $3^{\mathrm{o}}$ parto & 0,69 & 0,69 & 0,20 & 0,11 \\
\hline $4^{\mathrm{o}}$ parto & 0,64 & 0,75 & 0,91 & 0,18 \\
\hline
\end{tabular}

a Estimativas obtidas das análises bicaracterísticas entre as parições.

b Estimativas de cada ordem de parto são médias de três análises bicaracterísticas.

as correlações genéticas entre a primeira e a terceira e entre a segunda e a terceira parições foram geralmente altas $(0,77$ a 1,00$)$.

Segundo Hanenberg et al. (2001), a correlação genética para tamanho de leitegada entre parições excede 0,70 , exceto em alguns casos, entre a primeira e as posteriores parições (Alfonso et al., 1997; Irgang al.,1994; Knap et al., 1993; Roehe \& Kennedy, 1995; Tholen et al., 1996).

Hanenberg et al. (2001) observaram que a correlação genética entre as medidas das parições na terceira, quarta, quinta e sexta ordens foram raramente diferentes da unidade em todas as características reprodutivas avaliadas. So mente as medidas entre a primeira e as sucessivas parições apresentaram correlações genéticas que se distanciaram consideravelmente da unidade para a maioria das características avaliadas. Isso significa que para essas características a primeira ordem de parto é geneticamente diferente, comparada com parições posteriores. No entanto, segundo esses mesmos autores, algumas das características reprodutivas avaliadas também demonstraram baixa correlação genética entre a segunda parição e as demais.

As médias e as variâncias do tamanho de leitegada geralmente diferem ao longo da vida produtiva da porca (número de parições). Assim, é possível que diferentes genes ou diferentes combinações de genes estejam envolvidos em cada parição, em razão da maturação hormonal ou fisiológica das porcas (Noguera et al., 2002). Entretanto, alta correlação genética entre parições é esperada se muitos genes envolvidos na expressão do tamanho de leitegada nas diferentes parições forem os mesmos.

As correlações genéticas entre as parições para número de leitões nascidos vivos diferiram consideravelmente da unidade neste estudo, evidenciando que componentes genéticos desta característica são diferentes para cada ordem de parto. 
As correlações encontradas neste estudo comprovam que pouco êxito teria em se fazer seleção utilizando resposta correlacionada. Desse modo, as estimativas de correlação genética entre as parições indicam, por exemplo, que intensiva seleção na primeira ordem de parto não resultará em alta resposta correlacionada nas parições posteriores. Assim, a seleção com base somente na primeira ordem de parto poderá fornecer estimativas de ganhos genéticos viesados em um programa de melhoramento.

Correlações genéticas iguais a 1 , ou aproximadamente 1 , indicam que ganhos genéticos na primeira parição da porca garantem ganhos genéticos nas parições posteriores, com o benefício de reduzir o intervalo de geração e aumentar a intensidade de seleção, ou que o modelo de repetibilidade poderia ser utilizado para avaliar o tamanho de leitegada. Contudo, baixas correlações genéticas indicam que leitegadas de diferentes partos devem ser tratadas como características diferentes (Ollivier, 1982) e que outras formas de avaliação genética, como os modelos multicaracterísticos, deveriam ser usadas para predizer os valores genéticos. Nesse caso, diferentes razões da variância entre efeito aditivo e residual devem também ser consideradas para cada parição, em vez de uma única razão para todas as parições. Então, modelos multicaracterísticos são preferíveis nessa situação. Entretanto, muitos programas de melhoramento usam modelo de repetibilidade, sobretudo em virtude de sua simplicidade. Embora uma análise unicaracterística possa ser suficiente na avaliação genética de tamanho de leitegada, Alfonso et al. (1994) relataram que o modelo multicaracterístico deveria ser usado para evitar superestimação da resposta esperada à seleção.

O modelo multicaracterístico deve ser o objetivo final, se houver significativa divergência em estipular qual modelo utilizar quando os modelos de repetibilidade e multicaracterístico são equivalentes, conforme sumarizado por Henderson (1988). Primeiramente, a correlação genética entre parições deve ser igual a 1 no modelo de repetibilidade, porém as estimativas das correlações, dependendo da raça e da combinação de parições, são, às vezes, significativamente menores que 1 . Segundo, a variância genética deve ser igual no modelo de repetibilidade. Este estudo sugere que as variâncias genéticas entre as parições sejam diferentes e que a herdabilidade aumenta da primeira para a segunda e terceira parições. Terceiro, a variância e co-variância residuais devem ser iguais para assumir modelo de repetibilidade, mas, neste estudo, a variância residual foi substancialmente menor na primeira ordem de parto. Finalmente, as variâncias fenotípicas e as correlações entre as parições não foram iguais.

\section{Conclusões}

As correlações entre as parições indicam que o número de leitões nascidos nas diferentes parições deve ser tratado como características diferentes. Assim, recomenda-se utilizar tamanho de leitegada em parições diferentes como características diferentes em análise multicaracterística na avaliação genética dessa população de suínos.

\section{Literatura Citada}

ALFONSO, L.; NOGUERA, J.L.; BABOT, D. et al. Selection for litter size using a multivariate animal model. In: WORLD CONGRESS GENETICS APPLIED TO LIVESTOCK PRODUCTION, 5., 1994, Guelph. Anais... Guelph: 1994. p.347-350.

ALFONSO, L.; NOGUERA, J.L.; BABOT, D. et al. Estimates of genetic parameters for litter size at different parities in pigs. Livestock Production Science, v.47, p.149-156, 1997.

AVALOS, E.; SMITH, C. Genetic improvement of litter size in pigs. Animal Production, v.44, p.153, 1987.

BOLDMAN, K.G.; KRIESE L.A.; Van VLECK, L.D. et al. A manual for use of MTDFREML. A set of programs to obtain estimates of variance and covariance [Draft]. Lincoln: Department of Agriculture, Agriculture Research Service, 1995. 115p.

BOLET, G.; OLLIVIER, L.; DANDO, P. Selection sur la prolificité chez le porc. I. Resultats d'une experience de selection sur onze generations. Genetics Selection Evolution, v.2, p.93, 1989.

De VRIES, A.G.; KANIS, E. Swine breeding goals, shortand longterm considerations. In: WORLD CONGRESS GENETIC APPLIED LIVESTOCK PRODUCTION, 5., 1994, Guelph. Anais... Guelph: 1994. p.390-397.

ESTANY, J.; SORENSEN, D. Estimation of genetic parameters for litter size in Danish Landrace and Yorkshire pigs. Animal Science, v.60, p.315-324, 1995.

HALEY, C.S.; AVALOS, E.; SMITH, C. Selection for litter size in the pig. Animal Breeding Abstract, v.56, p.317-332, 1988.

HANENBERG, E.H.A.T.; KNOL, E.F.; MERKS, J.W.M. Estimates of genetic parameters for reproduction traits at different parities in dutch Landrace pigs. Livestock Production Science, v.69, p.179-186, 2001.

HENDERSON, C.R. Theoretical basis and computational methods for a number of different animal models. Journal of Dairy Science, v.71, p.1, 1988 (suppl. 2).

HERMESCH, S.; LUXFORD, B.G.; GRASER. H.U. Genetic parameters for lean meat yield, meat quality, reproduction and feed efficiency traits for australian pigs: 3 . Genetic parameters for reproduction traits and genetic correlations with production, carcass and meat quality traits. Livestock Production Science, v.65, p.261-270, 2000

IRGANG, R.; FAVERO, J.A.; KENNEDY B.W. Genetic parameters for litter size of different parities in Duroc, Landrace, and Large White sows. Journal of Animal Science, v.72, p.22372246, 1994.

KNAP, P.W.; Van ALST, G.J.M.; VERSTEEG, J.G. et al. Realized genetic improvement of litter size in Dutch. Pig Herdbook breeding. Pig News and Information, v.14, p.119-121. 1993.

LAMBERSON, W.R. Genetic parameters for reproductive traits. In: YOUNG, L.D. (Ed.) Genetics of swine. Clay Center: US Department of Agriculture, 1990. p.70-76.

LAMBERSON, W.R.; JOHNSON, R.K.; ZIMMERMAN, D.R. et al. Direct responses to selection for increased litter size, decreased age at puberty, or random selection following selection for ovulation rate in swine. Journal of Animal Science, v.69, p.3129-3143, 1991. 
Le ROY, P.; LEGAULT, C.; GRUAND, J. et al. Héritabilité réalisée pour la taille de portée dans la sélection de truies dites "hyperprolifiques". Genetics Selection Evolution, v.19, p.351-364, 1987.

LUKOVIÆ, Z.; MALOVRH, S; GORJANC, G. et al. A random regression model in analysis of litter size in pigs. South African Journal of Animal Science, v.34, n.4, p.241-248, 2004.

NOGUERA, J.L.; VARONA, L.; BABOT, D. et al. Multivariate analysis of litter size for multiple parities with production traits in pigs: I. Bayesian variance component estimation. Journal of Animal Science, v.80, p.2540-2547, 2002.

OLLIVIER, L. Selection for prolificacy in the pig. Pig News and Information, v.3, p.383, 1982.

ROEHE, R. Genetic determination of individual birth weight and its association with sow productivity traits using Bayesian analyses. Journal of Animal Science, v.77, p.330-343, 1999.

ROEHE, R.; KENNEDY, B.W. Estimation of genetic parameters for litter size in canadian Yorkshire and Landrace swine with each parity of farrowing treated as a different trait. Journal of Animal Science, v.73, p.2959-2970, 1995.

ROEHE, R.; KENNEDY, B.W. The influence of maternal effects on accuracy of evaluation of litter size in swine. Journal of Animal Science, v.71, p.2353-2364, 1993.

ROTHSCHILD M.F.; BIDANEL J.P. Biology and genetics of reproduction. In: ROTHSCHILD, M.F.; RUVINSKY, A. (Eds.) The genetics of the pig. Cambridge: CAB International, University Press, 1998. p.313-343.

SORENSEN, D. Predicted breeding values for litter size with an animal model used in the danish pig breeding program. Denmark: National Institute Animal Science, 1991 p.27. (Report).

SORENSEN, D.A.; VERNERSEN, A.H. Large scale selection for number of born piglets using an animal model. In: ANNUAL MEETING OF THE EUROPEAN ASSOCIATION FOR ANIMAL PRODUCTION, 42., 1991, Berlin. Anais... Berlin: 1991. (CD-ROM).

SOUTHWOOD, O.I.; KENNEDY, B.W. Genetic and environmental trends for litter size in swine. Journal of Animal Science, v.69, p.3177-3182, 1991.

TARTAR, M. Analyse critique des possibilités d'estimation du potentiel génétique des truies reproductrices. Paris: Université Paris-Sud, D. E. A. de Génétique Quantitative et Appliquée, 1981. 128p.

TARTAR, M.; BOLET, G., Application de la théorie des indices de sélection à des caractères répétés. Exemple de la sélection sur la prolificité chez le port. Genetics Selection Evolution, v.16, p.319-334, 1984.

THOLEN, E.; BUNTER, K.L.; HERMESCH, S. et al. The genetic foundation of fitness and reproduction traits in australian pig populations. 1. Genetic parameters for weaning to conception interval, farrowing interval, and stayability. Australian Journal of Agriculture Resource, v.47, p.1261-1274, 1996.

VANGEN, O. Genetic control of reproduction in pigs: from parturition to puberty. In: WORLD CONGRESS ON GENETICS APPLIED LIVESTOCK PRODUCTION, 3., 1986, Nebraska. Anais... Nebraska: 1986. p.168-179. 